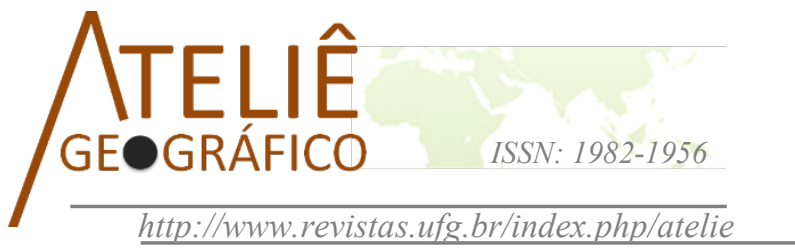

\section{Contribuição dos geoindicadores como ferramenta na identificação dos processos erosivos associados a Antropogeomorfologia}

\author{
Contribution of the geoindicators as a tool in the \\ identification of the erosive processes associated to \\ Anthropogeomorphology
}

\section{Contribución de los geoindicadores como herramienta en la identificación de los procesos erosivos asociados a Antropogeomorfología}

\author{
Ana Carolina Barbosa Pereira Dinotte \\ Instituto Federal de Educação, Ciência e Tecnologia de Minas Gerais \\ anacarolinna1@yahoo.com.br \\ Cecília Félix Andrade Silva \\ Instituto Federal de Educação, Ciência e Tecnologia de Minas Gerais \\ cecilia.andrade@ifmg.edu.br
}

\author{
Hygor Aristides Victor Rossoni \\ Universidade Federal de Viçosa \\ hygorrossoni@yahoo.com.br
}

\begin{abstract}
Resumo
As alterações de origens antrópicas identificadas nos processos de expansão urbana, supressão da vegetação, impermeabilização do solo, alterações no ciclo de drenagem e suas influências nas diversidades dos sistemas ambientais, são caracterizados como aspectos que podem gerar impactos ambientais negativos. A partir desta temática, se faz necessário o desenvolvimento de técnicas que possibilitem a compreensão da extensão temporal destas modificações. Desde então, a proposta de utilização de geoindicadores mais específicos, vem sendo amplamente abordada dentro do meio científico como um método de auxílio no reconhecimento das prováveis mudanças identificadas na paisagem, no espaço e escalas temporais que podem contribuir na identificação de prováveis impactos ambientais e ou no planejamento de ações mitigadoras. Assim, o presente artigo teve como objetivo compreender o papel dos geoindicadores na identificação das prováveis alterações originadas a partir de ações antropogênicas em ambientes urbanizados. Além disso, propõe apresentar e discutir
\end{abstract}


as diferentes propostas de geoindicadores que podem ser utilizados na identificação de modificações hidrogeomorfológicos diagnosticadas em áreas urbanas.

Palavras-chave: Geoindicadores. Geomorfologia antropogênica. Urbanização. Antropogeomorfologia

\begin{abstract}
Changes in anthropogenic sources identified in the processes of urban expansion, suppression of vegetation, soil sealing, changes in the drainage cycle and their influence on the diversity of environmental systems are characterized as aspects that can generate negative environmental impacts. From this theme, it is necessary to develop techniques that make possible the comprehension of the temporal extension of these modifications. Since then, the proposal for the use of more specific geoindicators has been widely considered within the scientific community as a method to aid in the recognition of the probable changes identified in the landscape, space and temporal scales that can contribute to the identification of probable environmental impacts and/or in the planning of mitigating actions. Thus, the present article aimed to understand the role of geoindicators in the identification of probable changes originating from anthropogenic actions in urbanized environments. In addition, it proposes to present and discuss the different proposals of geoindicators that can be used in the identification of hydrogeomorphological modifications diagnosed in urban areas.

Keywords: Geoindicators. Anthropogenic geomorphology. Urbanization. Anthropogeomorphology
\end{abstract}

\begin{abstract}
Resumen
Las alteraciones de orígenes antrópicos identificados en los procesos de expansión urbana, supresión de la vegetación, impermeabilización del suelo, cambios en el ciclo de drenaje y sus influencias en las diversidades de los sistemas ambientales, se caracterizan como aspectos que pueden generar impactos ambientales negativos. A partir de esta temática, se hace necesario el desarrollo de técnicas que posibilite la comprensión de la extensión temporal de estas modificaciones. Desde entonces, la propuesta de utilización de geoindicadores más específicos, viene siendo ampliamente abordada dentro del medio científico como un método de ayuda en el reconocimiento de los probables cambios identificados en el paisaje, en el espacio y escalas temporales que pueden contribuir en la identificación de probables impactos ambientales y/o en la planificación de acciones mitigadoras. Así, el presente artículo tuvo como objetivo comprender el papel de los geoindicadores en la identificación de las probables alteraciones originadas a partir de acciones antropogénicas en ambientes urbanizados. Además, propone presentar y discutir las diferentes propuestas de geoindicadores que pueden ser utilizados en la identificación de modificaciones hidrogeomorfológicas diagnosticadas en áreas urbanas.
\end{abstract}

Palabras clave: Geoindicadores. Geomorfología antropogénica. Urbanización. Antropogeomorfologia

\title{
Introdução
}

A população mundial que vive em centros urbanos deve passar de $54 \%$ para $66 \%$ até 2050. As projeções indicam que o processo de urbanização associado ao crescimento da população mundial deve inserir em torno de 2,5 milhões de pessoas em áreas urbanizadas e projeta que $90 \%$ deste incremento deve ocorrer nos continentes Asiático e Africano, sendo esses, os que absorverão o maior número de novos habitantes. 
Outra abordagem descrita no relatório "Perspectivas da Urbanização Mundial, 2014" (World Urbanization Prospects) desenvolvido pela Divisão das Nações Unidas para a População do Departamento dos Assuntos Económicos e Sociais (DESA) se trata do aumento de dezoito megas-cidades entre os anos de 1990 a 2014. Atualmente, existem vinte e oito megas-cidades distribuídas em todo o mundo, sendo que dezesseis destas estão localizadas no continente Asiático, quatro na América Latina, três na África e na Europa, e duas na América do Norte (Nações Unidas, 2014).

No Brasil, as megas-cidades são os municípios de São Paulo com aproximadamente 20,8 milhões de habitantes em áreas urbanas e Rio de Janeiro com 12,8 milhões. As projeções destacam que até 2050 , aproximadamente $79 \%$ da população deva optar por residir em grandes centros urbanos. O município de São Paulo está em quinto lugar em comparação com os países de maior número de habitantes, ficando atrás apenas de Tóquio (Japão), com 37,8 milhões, Deli (Índia), com 24,9 milhões, Xangai (China), com 22,9 milhões, e México (México) com 20,8 milhões. Neste ranking, Belo Horizonte ocupa o quinquagésimo nono lugar, com aproximadamente 5,6 milhões de habitantes residentes em centros urbanos (Nações Unidas, 2014).

A crescente demanda da população de se apropriar de grandes centros urbanos, promove o aparecimento da abordagem e discussão dos impactos ambientais negativos associados as ações antropogênicas. Estes impactos são provenientes do processo de modificações originadas a partir das interferências e interrelações dos indivíduos com o equilíbrio dinâmico da natureza. As alterações originadas a partir destas interferências afetam diretamente os processos naturais diversos, modificando sua paisagem e gerando alterações que possam apresentar consequências para a sociedade que habita em áreas urbanas (RODRIGUES, 2010).

Peloggia (2005), afirma que um dos aspectos de alterações dos processos naturais mais significativos e mais evidentes na superfície da Terra são modificações no relevo causadas pelas ações dos indivíduos. As modificações morfoesculturais (erosivos) e de seus depósitos correlativos marcam características de um período intitulado como Tecnógeno, termo utilizado para abordar a situação geológico-geomorfológica atual na qual se tem a presença do indivíduo como agente de modificação.

As referências diretas que os indivíduos são agentes Geomorfológicos surgem no século XX e deu-se a partir das pesquisas de Nir (1983). Em suas obras o autor apresenta o conceito de Geomorfologia Antrópica e propõe a análise das alterações antes das interferências causadas a partir das ações antrópicas e após tais influências. Esta abordagem caracteriza as ações antrópicas como atuantes na modelagem das formas, dos materiais e dos processos observados na Terra, outras importantes contribuições e propostas metodológicas são apresentadas por Goudie (1993), Coltrinari (2001), Gupta (2002) e Rodrigues (2010) e serão descritas a seguir.

Nesse contexto, a utilização de indicadores como ferramenta de análise do nível de degradação dos ecossistemas teve início no final da década de 1940, porém teve seu 
auge com a publicação em 1987 do relatório Brundtland World Commission on Environment and Development (Comissão Mundial sobre Meio Ambiente e Desenvolvimento). Esta publicação referência a importância da adoção de medidas sociais e econômicas na manutenção do equilíbrio dos ecossistemas e da população. As contribuições dos relatórios de estado do ambiente (SOE), abordam os fatores de biodiversidade associados aos ecossistemas, propondo como por exemplo, a avaliação da qualidade da água e da qualidade do ar, se valendo assim, de parâmetros biológicos e químicos. Porém, demonstra deficiência quanto a ausência da citação das ações humanas como agente atuante nas alterações ambientais (BERGER, 1997).

A abordagem ampla das ações antrópicas nos ambientes terrestres, teve maior incentivo de pesquisa a partir dos eventos Rio 92 - Cúpula da Terra e Agenda 21. Em 1994 foi criado pela Comissão de Ciências Geológicas para Planejamento Ambiental COGEOENVIRONMENT um grupo de trabalho que teve como objetivo a elaboração de uma lista com 27 geoindicadores que apresentam as prováveis mudanças de aspectos geológicos e geomorfológicas que poderiam ser identificados em intervalos temporais (COLTRINARI, 2001).

Segundo Coltrinari (2001 p. 307), “As mudanças ambientais globais são transformações no ambiente terrestre - geosfera, e na vida que o habita - biosfera, parte inseparável do Sistema Terra". Propõe uma visão integrada destas mudanças relacionando-as com as alterações que ocorrem na atmosfera, nos oceanos, na presença de gelo e terras imersas, bem como através dos processos biológicos. Afirma também que estas modificações se darão por meio da integração de escalas temporais e espaciais, sendo estas determinadas mediante análises das possíveis mudanças ambientais.

Porém, uma das dificuldades apontadas por Coltrinari (2001), está associada a limitação de identificar as mudanças ambientais rápidas de menor escala de amplitude, daquelas que apresentam impactos mais restritos, distinguindo-as assim das consequências de ordem natural das de ordem antrópica. Sendo assim, a utilização destes geoindicadores poderia esclarecer e facilitar a compreensão das mudanças naturais das de origem antrópica.

Partindo deste contexto e considerando o cenário atual, o presente trabalho visa elaborar uma revisão sistemática da literatura, acerca dos geoindicadores aplicados na atualidade relacionadas a avaliação e quantificação dos efeitos e consequências das ações antropogênicas em uma escala temporal na modificação geomorfológica. Dessa forma, a proposta da revisão sistemática visa compreender se a adoção de geoindicadores podem contribuir na identificação das prováveis alterações geradas a partir de ações antropogênicas em ambientes urbanizados. Além disso, propõe apresentar e discutir as diferentes propostas de geoindicadores que podem ser utilizados na identificação de modificações hidrogeomorfológicos diagnosticadas em áreas urbanas. 


\section{Metodologia de trabalho}

A partir da definição do objetivo descrito neste trabalho, foram realizados levantamentos de artigos de publicações científicas, que abordaram a temática das metodologias de identificação e quantificação das alterações hidrogeomorfológicas causadas por ações antropogênicas.

Foram realizadas buscas de referencial teórico utilizando a Plataforma Periódicos CAPES. Para tanto, utilizou-se os seguintes termos de busca: Geoindicadores, Geomorfologia antropogênica e Urbanização.

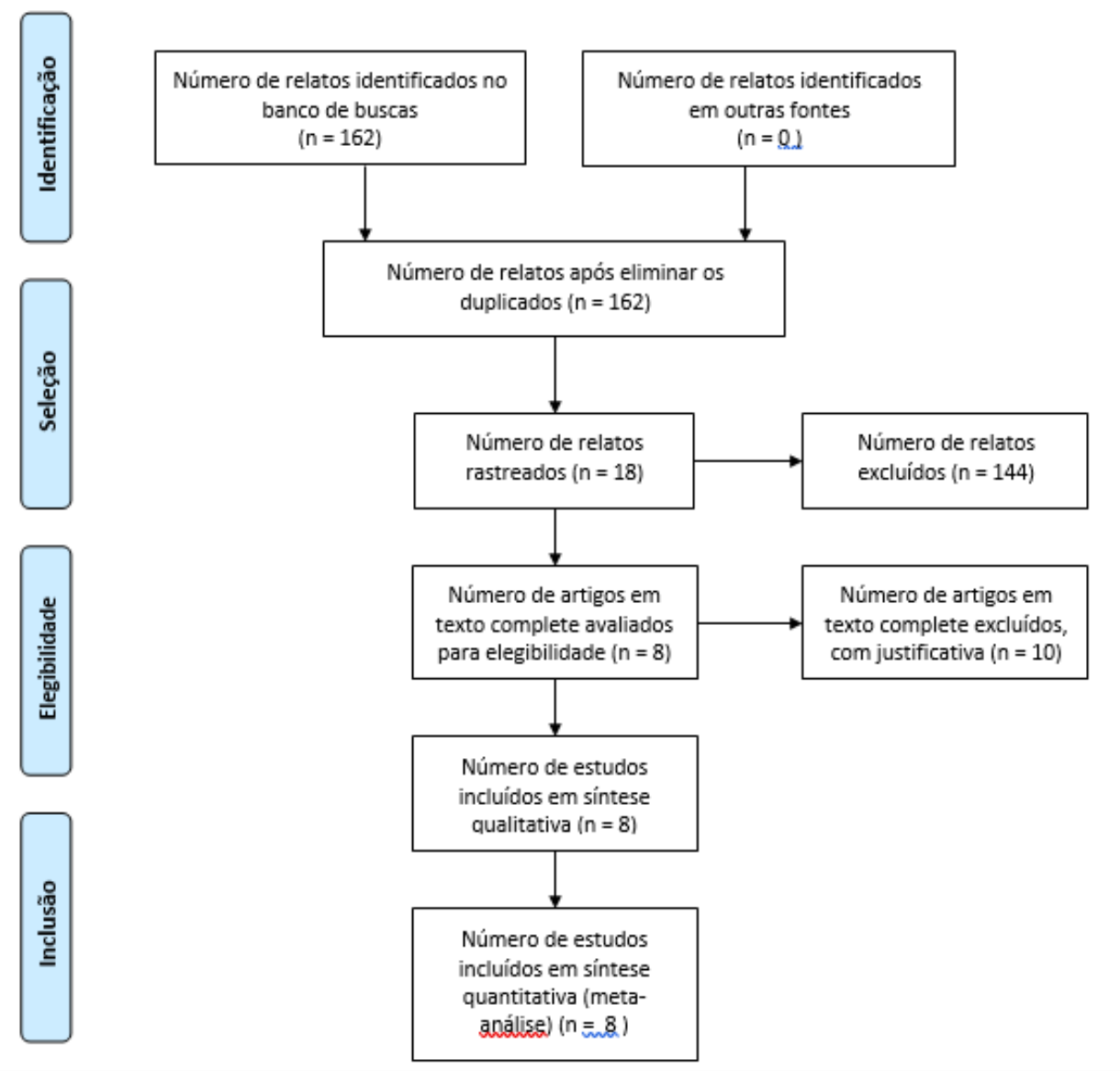

Figura 01: Fluxo da informação com as diferentes fases de uma revisão sistemática Fonte: Moher et al. 2009 
O processo de seleção dos artigos para compor este trabalho, seguiram as diretrizes propostas no fluxograma de análise das diferentes fases de elaboração de uma revisão sistemática. Na Figura 01, encontra-se apresentado o fluxograma de prisma, conforme modelo proposto por Moher et al. 2009, contendo o fluxo de informações nas diferentes fases de elaboração e seleção dos artigos utilizados no presente trabalho.

$\mathrm{Na}$ etapa de seleção dos artigos, foram identificados e escolhidos aqueles que estavam associados ao "tema de indicadores de avaliação das mudanças antropogênicas do processo de urbanização na modificação do relevo".

Além do processo de seleção, realizado por meio da avaliação do tema, utilizouse também da análise prévia do título, resumo, palavras chave, análise da introdução e conclusão.

Utilizaram-se como critério de exclusão das etapas de seleção e elegibilidade, os artigos que tratavam de aspectos antropogênicos fora do escopo de urbanização, como por exemplo, fatores relacionados as mudanças climáticas, mudanças no ambiente marinho e alterações de cursos d'água.

As etapas de elegibilidade e inclusão consistem nas duas últimas fases, onde os artigos selecionados passaram por uma avaliação completa na qual as abordagens são descritas nesta revisão sistemática. Os resultados das buscas geradas a partir da utilização do diagrama de prisma (figura I), foram analisados e contribuíram para a construção da tabela 01, que fundamentaram a etapa de discussões dos resultados apresentados nesta revisão sistemática.

Tabela 01: Referências bibliográficas selecionadas para comporem a presente revisão sistemática de literatura.

\begin{tabular}{|c|c|c|c|c|}
\hline Periódicos & Autores & Título & $\begin{array}{l}\text { Classificação } \\
\text { Qualis/Capes }\end{array}$ & $\begin{array}{l}\mathbf{N}^{0} \text { de } \\
\text { Citações }\end{array}$ \\
\hline $\begin{array}{l}\text { Environmental } \\
\text { Geology. } \\
\text { July } 1997\end{array}$ & $\begin{array}{l}\text { BERGER, } \\
\text { A.R. }\end{array}$ & $\begin{array}{l}\text { Assessing rapid } \\
\text { environmental change } \\
\text { using geoindicators }\end{array}$ & B1 & 62 citações \\
\hline Objetivos & \multicolumn{4}{|c|}{$\begin{array}{l}\text { i) Apresenta revisões de geoindicadores associados aos diferentes ambientes } \\
\text { geológicos, terrenos glaciais, sistemas de água subterrânea, costas, desertos, } \\
\text { lagos, zonas húmidas, solos e recifes de coral. } \\
\text { ii) Apresenta lista de verificação internacional de geoindicadores. }\end{array}$} \\
\hline $\begin{array}{l}\text { Geomorpholog } \\
\text { y } \\
1993\end{array}$ & $\begin{array}{l}\text { GOUDIE, } \\
\text { Andrew }\end{array}$ & $\begin{array}{l}\text { Human influence in } \\
\text { geomorphology }\end{array}$ & A1 & 49 citações \\
\hline Objetivos & \multicolumn{4}{|c|}{$\begin{array}{l}\text { i) Perspectivas sobre as direções futuras da pesquisa em geomorfologia e } \\
\text { compreensão dos mecanismos de resposta das alterações do relevo. }\end{array}$} \\
\hline $\begin{array}{l}\text { Environmental } \\
\text { Geology. } 2002\end{array}$ & $\begin{array}{l}\text { GUPTA, } \\
\text { Avijit }\end{array}$ & $\begin{array}{l}\text { Geoindicators for tropical } \\
\text { urbanization. } \\
\text { Environmental Geology }\end{array}$ & B1 & 57 citações \\
\hline Objetivos & \multicolumn{4}{|c|}{$\begin{array}{l}\text { i) Apresentação de uma seleção de geoindicadores que podem ser utilizados } \\
\text { para quantificar os impactos causados pelas ações antrópicas. }\end{array}$} \\
\hline
\end{tabular}




\begin{tabular}{|c|c|c|c|c|}
\hline Periódicos & Autores & Título & $\begin{array}{l}\text { Classificação } \\
\text { Qualis/Capes }\end{array}$ & $\begin{array}{c}N^{0} \text { de } \\
\text { Citações }\end{array}$ \\
\hline $\begin{array}{l}\text { Revista do } \\
\text { Departamento } \\
\text { de Geografia. } \\
2010\end{array}$ & $\begin{array}{l}\text { RODRIGUE } \\
\text { S, Cleide. }\end{array}$ & $\begin{array}{l}\text { Avaliação do impacto } \\
\text { humano da urbanização em } \\
\text { sistemas } \\
\text { hidrogeomorfológicos. } \\
\text { Desenvolvimento e } \\
\text { aplicação de metodologia } \\
\text { na grande São Paulo. }\end{array}$ & A2 & 24 citações \\
\hline Objetivos & \multicolumn{4}{|c|}{$\begin{array}{l}\text { i) Apresentar os resultados da aplicação da metodologia de identificação dos } \\
\text { impactos e efeitos que o extenso e duradouro processo de intervenção } \\
\text { antrópica da urbanização de São Paulo produziu ao longo dos últimos cem } \\
\text { anos em sistemas hidrogeomorfológicos. }\end{array}$} \\
\hline $\begin{array}{l}\text { Pesquisas em } \\
\text { Geociências. } 20 \\
01\end{array}$ & $\begin{array}{l}\text { COLTRINARI, } \\
\text { Lylian }\end{array}$ & $\begin{array}{l}\text { Mudanças ambientais } \\
\text { globais e geoindicadores }\end{array}$ & & 10 citações \\
\hline Objetivos & \multicolumn{4}{|c|}{$\begin{array}{l}\text { i) Apresenta revisões de propostas de geoindicadores correlacionando as } \\
\text { mudanças globais nos trópicos, degradação da floresta e do solo, a } \\
\text { contribuição do processo de mineração, o crescimento urbano, acidificação do } \\
\text { ar e suas interrelações. }\end{array}$} \\
\hline $\begin{array}{l}\text { Revista GEO } \\
\text { USP - Espaço } \\
\text { e Tempo - } \\
2017\end{array}$ & $\begin{array}{l}\text { MOROZ- } \\
\text { CACCIA } \\
\text { Gouveia, Isabel } \\
\text { Cristina e } \\
\text { RODRIGUES, } \\
\text { Cleide }\end{array}$ & $\begin{array}{l}\text { Mudanças morfológicas e } \\
\text { efeitos hidrodinâmicos do } \\
\text { processo de urbanização na } \\
\text { bacia hidrográfica do rio } \\
\text { Tamanduateí - } \\
\text { Região Metropolitana de S } \\
\text { Paulo. }\end{array}$ & 1 & ND \\
\hline
\end{tabular}

Objetivos

i) Identificar e analisar as mudanças morfológicas impostas pela ocupação urbana à bacia hidrográfica do rio Tamanduateí/SP.

\begin{tabular}{|c|c|c|c|}
\hline $\begin{array}{l}\text { Tese } \\
\text { (Doutorado em } \\
\text { Geografia), } \\
\text { Faculdade de } \\
\text { Filosofia, } \\
\text { Letras e } \\
\text { Ciências } \\
\text { Humanas, } \\
\text { Universidade } \\
\text { de São Paulo. } \\
\text { São Paulo, } \\
\text { 2015. }\end{array}$ & $\begin{array}{l}\text { LUZ, Rodolfo } \\
\text { Alves }\end{array}$ & $\begin{array}{l}\text { Mudanças geomorfológicas } \\
\text { na planície fluvial do Rio } \\
\text { Pinheiros, São Paulo (SP), } \\
\text { ao longo do processo de } \\
\text { urbanização. }\end{array}$ & ND \\
\hline Objetivos & $\begin{array}{l}\text { i) Identificação } \\
\text { identificadas na } \\
\text { com regiões sel }\end{array}$ & $\begin{array}{l}\text { mudanças de origem antrópicas c } \\
\text { nície fluvial do Rio Pinheiros e c } \\
\text { tantes com pouca perturbação ant }\end{array}$ & $\begin{array}{l}\text { reta } \\
\text { tes resultados }\end{array}$ \\
\hline
\end{tabular}




\begin{tabular}{|c|c|c|c|c|}
\hline Periódicos & Autores & $\begin{array}{l}\text { Clas } \\
\text { Qual }\end{array}$ & $\begin{array}{l}\text { sificação } \\
\text { is/Capes }\end{array}$ & $\begin{array}{l}\mathbf{N}^{0} \text { de } \\
\text { Citações }\end{array}$ \\
\hline $\begin{array}{l}\text { Revista } \boldsymbol{R a} \boldsymbol{a}^{\boldsymbol{e}} \\
\boldsymbol{G a} \text { - O Espaço } \\
\text { Geográfico em } \\
\text { Análise - } \\
\text { Agosto/17 }\end{array}$ & $\begin{array}{l}\text { MARQUES } \\
\text { NETO, Roberto } \\
\text { Marques, } \\
\text { SILVA, Felipe } \\
\text { Pacheco } \\
\text { FERNANDES, } \\
\text { Rodinei de } \\
\text { Almeida, } \\
\text { BARRETO, } \\
\text { Juliana Costa, } \\
\text { EDUARDO, } \\
\text { Carolina } \\
\text { Campos. }\end{array}$ & $\begin{array}{l}\text { A espacialidade do relevo } \\
\text { em paisagens transformadas } \\
\text { e sua representação: } \\
\text { Mapeamento } \\
\text { geomorfológico da bacia do } \\
\text { rio Paraibuna, sudeste de } \\
\text { Minas Gerais }\end{array}$ & 2 & ND \\
\hline
\end{tabular}

\section{Objetivos}
i) Propõe o mapeamento geomorfológico para a bacia do rio Paraibuna, localizado na porção sudeste do estado de Minas Gerais, objetiva a avaliação do papel da cartografia na interpretação da espacialidade do relevo em paisagens intensivamente transformadas onde as morfologias e processos antropogênicos é que dão a tônica ao sistema geomorfológico.

Em que: ND = não disponível

Fonte: Elaborado pela autora, 2018.

\section{Resultados e discussões}

Segundo Berger (1997), geoindicadores são um conjunto de parâmetros observados na superfície da Terra. A proposta de adoção destes geoindicadores são determinantes dentro de uma perspectiva de avaliação ambiental, que por sua vez são definidos e avaliados a partir da magnitude, frequência, taxas ou tendências geológicas em um período de 100 anos ou menos. A análise temporal realizada durante a caracterização destes geoindicadores é fundamental para a compreensão das mudanças ambientais rápidas que contribuem na modificação da paisagem. Estes indicadores foram propostos pelo grupo de trabalho da Comissão de Ciências Geológicas para Planejamento Ambiental - COGEOENVIRONMENT da União Internacional de Ciências Geológicas do International Union of Geological Science (IUGS).

Segundo Berger (1997), dentre os geoindicadores propostos através do grupo de trabalho da Comissão de Ciências Geológicas para Planejamento Ambiental COGEOENVIRONMENT, foram selecionados 27 geoindicadores (tabela II), sendo que a escolha destes geoindicadores, expressam aqueles que melhor auxiliam na identificação das prováveis mudanças identificadas na paisagem, em ordens temporais distintas e que possam contribuir na identificação de prováveis impactos ambientais e ou no planejamento de ações mitigadoras. A lista completa dos indicadores está apresentada na tabela 02 . 
Tabela 02: Geoindicadores

\begin{tabular}{|c|c|}
\hline Geoindicadores & Mudanças ambientais \\
\hline Química do coral e padrão de crescimento & $\begin{array}{l}\text { Temperatura da água de superfície e } \\
\text { salinidade }\end{array}$ \\
\hline Crostas e fissuras em superfície dessértica & Aridez \\
\hline Formação e reativação de dunas & $\begin{array}{l}\text { Velocidade e direção dos ventos, umidade, } \\
\text { aridez e disponibilidade de sedimentos }\end{array}$ \\
\hline $\begin{array}{l}\text { Magnitude, duração e frequência de } \\
\text { tempestade de areia. }\end{array}$ & Transporte de areia, aridez e uso do solo \\
\hline Atividade de solo congelado & Clima, Hidrologia e movimentação de taludes \\
\hline Flutuações de geleiras & $\begin{array}{l}\text { Precipitação, insolação e fluxo de } \\
\text { derretimento }\end{array}$ \\
\hline Qualidade da água subterrânea & $\begin{array}{l}\text { Uso do solo, contaminação, alteração de } \\
\text { rocha e solo, radiatividade e precipitação de } \\
\text { ácidos }\end{array}$ \\
\hline $\begin{array}{l}\text { Química da água subterrânea na zona não } \\
\text { contaminada }\end{array}$ & $\begin{array}{l}\text { Alteração de solos e rochas, clima e uso do } \\
\text { solo }\end{array}$ \\
\hline Nível da água subterrânea & Clima, impermeabilização e recarga \\
\hline Atividade kárstica & $\begin{array}{l}\text { Clima e fluxo de água subterrânea, clima, } \\
\text { cobertura vegetal e processos fluviais }\end{array}$ \\
\hline Níveis e salinidade de lagos & $\begin{array}{l}\text { Clima, uso do solo, vazão e circulação da } \\
\text { água subterrânea }\end{array}$ \\
\hline Nível relativo do mar & $\begin{array}{l}\text { Oscilação nas linhas de costa, clima, } \\
\text { extração de fluidos, sedimentação e } \\
\text { compactação }\end{array}$ \\
\hline Sequência e composição de sedimentos & Clima, uso do solo, erosão e deposição \\
\hline Sismicidade & Tensões naturais ou induzidas \\
\hline Linha da costa & $\begin{array}{l}\text { Erosão costeira, transporte e deposição de } \\
\text { sedimentos, uso do solo, nível do mar e } \\
\text { clima }\end{array}$ \\
\hline Deslizamentos de encostas & $\begin{array}{l}\text { Estabilidade de taludes, movimentos de } \\
\text { massa e uso do solo }\end{array}$ \\
\hline Erosão de solos e sedimentos & $\begin{array}{l}\text { Clima, tempestade de água, vento e uso do } \\
\text { solo }\end{array}$ \\
\hline Qualidade do solo & $\begin{array}{l}\text { Processos químicos, biológicos e físicos no } \\
\text { solo e uso do solo }\end{array}$ \\
\hline Fluxo de corrente & $\begin{array}{l}\text { Clima, precipitação, bacia de drenagem e uso } \\
\text { do solo }\end{array}$ \\
\hline Morfologia de canal & $\begin{array}{l}\text { Carga de sedimentos, velocidade de fluxo, } \\
\text { clima, uso do solo e subsidência }\end{array}$ \\
\hline $\begin{array}{l}\text { Armazenamento e carga de fluxo de } \\
\text { sedimento }\end{array}$ & $\begin{array}{l}\text { Transporte de sedimento, taxa de fluxo, } \\
\text { bacia de drenagem e uso do solo }\end{array}$ \\
\hline
\end{tabular}




\begin{tabular}{l|l}
\hline Geoindicadores & Mudanças ambientais \\
\hline Regime de temperatura de subsuperfície & $\begin{array}{l}\text { Clima, fluxo de calor, uso do solo e } \\
\text { cobertura vegetal }\end{array}$ \\
\hline Deslocamentos crustais & $\begin{array}{l}\text { Soerguimento e subsistência, falhamentos e } \\
\text { extração de fluídos }\end{array}$ \\
\hline Qualidade de água de superfície & $\begin{array}{l}\text { Clima, uso de solo, interações água-solo- } \\
\text { rocha e velocidade de fluxo }\end{array}$ \\
\hline Atividade vulcânica & $\begin{array}{l}\text { Movimento de magma próximo a superfície, } \\
\text { liberação de gases magmáticos e fluxo de } \\
\text { calor }\end{array}$ \\
\hline $\begin{array}{l}\text { Extensão, estrutura e hidrologia de terras } \\
\text { úmidas }\end{array}$ & $\begin{array}{l}\text { Uso do solo, clima, produtividade biológica e } \\
\text { vazão de fluxo. }\end{array}$ \\
\hline Erosão eólica & Clima, uso do solo e cobertura vegetal \\
\hline
\end{tabular}

Fonte: Elaborado por Berger (1997 p. 39), tradução de Tavares, 2007.

Dentre os métodos de avaliação das alterações antrópicas proposto por Berger (1997), estão relacionados alguns dos seguintes indicadores, sendo eles: indicadores de qualidade água, nível da águas subterrânea e química da água presente nestes ambientes, qualidade do solo, processos erosivos, atividades vulcânicas e sísmicas, atividade cárstica, instabilidade das vertentes, intensidade das inundações, alteração dos canais fluviais, fatores associados a mudança da temperatura, precipitação, evapotranspiração e uso da terra (BERGER, 1997).

Os indicadores propostos por Coltrinari (2001), se assemelham a proposta de Berger (1997), a medida que propõem a realização de análise e identificação das possíveis mudanças na paisagem em ordens temporais distintas, considerando que estas avaliações podem contribuir na identificação de prováveis impactos ambientais e ou no planejamento de ações mitigadoras. Segundo Coltrinari (2001), os geoindicadores podem ser avaliados dentro de uma escala espaço-temporal variável, parâmetro esse que deverá ser definido a partir do objetivo da pesquisa e através das variáveis como dimensão territorial da área a ser pesquisada e duração e periodicidade dos aspectos a serem mapeados. Entre os parâmetros Coltrinari (2001 p. 312), afirma que: "merecem atenção especial a distribuição sazonal da chuva, os ciclos vegetais e o ciclo anual das queimadas, capazes de causar mudanças importantes nos geoindicadores na zona tropical úmida".

A partir das pesquisas elaborados por Coltrinari (2001 p. 312), os seguintes geoindicadores de monitoramento de alterações antrópicas em ambientes de zona tropical úmida são propostos:

Erosão do solo (fluxos superficiais e movimentos de massa), erosão remontante nas cabeceiras, expansão das superfícies de solo descoberto, mudanças de fluxo não concentrado a concentrado, morfometria e morfologia das vertentes, movimentos de massa e sinais de movimentos futuros, morfologia dos canais fluviais, 
vazão e carga sólida dos rios, coluvionamento e aluvionamento, conteúdo de matéria orgânica no solo, volume e área dos depósitos tecnogênicos, erosão e sedimentação costeiras, deltas, mudanças qualitativas e quantitativas na cobertura vegetal e poluição/acidificação de ar, a terra e a água.

Segundo Gupta (2002), uma das formas de avaliar e quantificar as mudanças antrópicas em ambientes urbanos também está pautada na adoção de Geoindicadores. A aplicação da metodologia auxilia na geração de respaldo científico para a tomadas de decisões de gerenciamento para os grandes centros urbanos. Propõe que o monitoramento de indicadores urbanos, deva aferir processos de diminuição, aumento e transferência de água subterrânea, inundações, instabilidade das vertentes, perturbações sísmicas, alterações nas características do solo, riscos vulcânicos no caso de regiões localizadas a margem de placas tectônicas. Diante do ritmo acelerado do processo de urbanização e degradação física nos trópicos, o autor recomenda a avaliação de características intrínsecas a urbanização, como avaliação dos índices de precipitação e evapotranspiração, alterações da cobertura do solo e diferentes métodos de uso da terra, diminuição de águas residuais e a mudança de temperatura.

Rodrigues (2010), também propõem a adoção de geoindicadores na análise dos impactos de origem antrópica causados pelo processo de urbanização nas prováveis alterações da hidrogeomorfologia do meio trópico úmido, considerando intervalos temporais de cem anos. A metodologia indicada está respaldada nos princípios da Geografia física, Geomorfologia teórica, Geomorfologia antropogênica, apoiados em procedimentos da Cartografia e devem em todos os parâmetros seguir a avaliação dos fatores antropogênicos em diferentes escalas temporais e espaciais.

Os geoindicadores propostos por Rodrigues (2010, p.118), foram concebidos objetivando a quantificação da interferência que as ações antrópicas causam aos meios naturais e descreve que:

[...] está estruturado em parâmetros de grupo e, por tipo (formas, materiais e processos antropogênicos ou originais), por escala e por sistemas geomorfológicos, apresentando-se as respectivas unidades de medida e intervalos temporais recomendados para o monitoramento. Trata-se de lista metodologicamente construída para leituras quantitativas isoladas ou correlacionadas e passíveis de interpretações na perspectiva da ciência geomorfológica.

Uma das principais contribuições desta metodologia está associada a inclusão da antropogeomorfologia e da cartografia geomorfológica temporal. Além disso, a perspectiva desta metodologia permite a aplicação de indicadores a fim de identificar de forma qualitativa e quantitativa as prováveis intervenções antrópicas em sistemas hidrogeomorfológicos, principalmente para o meio tropical úmido (RODRIGUES, 2010).

São apresentados na tabela 03 alguns dos geoindicadores propostos por Rodrigues (2010), demostrando assim, uma preocupação do autor em definir parâmetros 
e indicadores capazes de identificar e mensurar as alterações geomorfológicas de origem antrópicas recorrentes em ambientes urbanos. São propostos geoindicadores de avaliação dos sistemas: Bacia hidrográfica, canais fluviais, planícies, planícies de inundação, conjuntos ou unidades de vertentes, interflúvios, reservatórios, remansos e reservatórios de lagos, vales. Atrelado a esses sistemas são propostas análises de natureza e escala temporal, parâmetros para avaliação dos sistemas, unidades de mensuração e instrumentos básicos necessários que auxiliaram o pesquisador no mapeamento e quantificação dos geoindicadores.

Tabela 03: Indicadores Morfológicos propostos por Rodrigues (2010)

\begin{tabular}{|c|c|c|c|c|}
\hline $\begin{array}{l}\text { Sistema } \\
\text { Indicador }\end{array}$ & $\begin{array}{l}\text { Natureza } \\
\text { /Escala }\end{array}$ & Parâmetro & Unidade & $\begin{array}{l}\text { Instrumentos } \\
\text { básicos }\end{array}$ \\
\hline $\begin{array}{l}\text { Bacia } \\
\text { hidrográfica }\end{array}$ & $\begin{array}{l}\text { Original } \\
\text { Pré-Antropogênico } \\
\text { Antropogênico }\end{array}$ & $\begin{array}{l}\text { Área } \\
\text { Forma } \\
\text { Localização }\end{array}$ & $\begin{array}{l}\mathrm{m}^{2} \text { ou } \mathrm{km}^{2} \\
\text { Década/Ano/Mês }\end{array}$ & $\begin{array}{l}\text { Cartografia } \\
\text { (documentos } \\
\text { antigos ou } \\
\text { recentes) }\end{array}$ \\
\hline $\begin{array}{l}\text { Bacia } \\
\text { hidrográfica }\end{array}$ & $\begin{array}{l}\text { Original } \\
\text { Pré-Antropogênico } \\
\text { Antropogênico }\end{array}$ & $\begin{array}{l}\text { Densidade de drenagem } \\
\text { (DD) ou } \\
\text { Coeficiente de } \\
\text { manutenção (CM) }\end{array}$ & $\begin{array}{l}\text { DD ou Co } \\
/ \text { década/ano } / \mathrm{mês} \\
\mathrm{km} / \mathrm{km}^{2} \\
\mathrm{~m}^{2} / \mathrm{m}\end{array}$ & $\begin{array}{l}\text { Cartografia } \\
\text { (documentos } \\
\text { antigos ou } \\
\text { recentes } \\
\text { /aerofotos) } \\
\end{array}$ \\
\hline $\begin{array}{l}\text { Sistema } \\
\text { Indicador }\end{array}$ & $\begin{array}{l}\text { Natureza } \\
\text { /Escala }\end{array}$ & Parâmetro & Unidade & $\begin{array}{l}\text { Instrumentos } \\
\text { básicos }\end{array}$ \\
\hline $\begin{array}{l}\text { Bacia } \\
\text { hidrográfica }\end{array}$ & $\begin{array}{l}\text { Original } \\
\text { Pré-Antropogênico } \\
\text { Antropogênico }\end{array}$ & Direção de fluxo & $\begin{array}{l}\text { Extensão } \\
\text { total/década/ano } \\
\text { /mês }\end{array}$ & $\begin{array}{l}\text { Cartografia } \\
\text { (documentos } \\
\text { antigos ou } \\
\text { recentes } \\
\text { /aerofotos) }\end{array}$ \\
\hline $\begin{array}{l}\text { Planície de } \\
\text { inundação }\end{array}$ & $\begin{array}{l}\text { Original } \\
\text { Pré-Antropogênico } \\
\text { Antropogênico }\end{array}$ & Área & $\begin{array}{l}\mathrm{m}^{2} \text { ou } \mathrm{km}^{2} \\
\text { Década/Ano/Mês }\end{array}$ & $\begin{array}{l}\text { Cartografia } \\
\text { Geomorfológicas } \\
\text { retrospectiva }\end{array}$ \\
\hline $\begin{array}{l}\text { Planície de } \\
\text { inundação }\end{array}$ & $\begin{array}{l}\text { Original } \\
\text { Pré-Antropogênico } \\
\text { Antropogênico }\end{array}$ & Altitude & Década/ano/mês & $\begin{array}{l}\text { Perfis } \\
\text { topográficos } \\
\text { antigos e recentes }\end{array}$ \\
\hline
\end{tabular}

Fonte: Rodrigues, 2010.

A metodologia proposta por Rodrigues (2010), já tratados por Goudie (1993), Coltrinari (2001), Gupta (2002), auxiliam na compreensão das mudanças antropogênicas do processo de urbanização na modificação do relevo. Além disso, tem como perspectiva analítica que o indivíduo interfere como agente modelador nas alterações geomorfológicas, modificando assim, os materiais e os processos originais, desencadeando em novos processos morfológicos. Conclui-se então, que a metodologia 
proposta tem como objetivo a avaliação e quantificação das consequências destas modificações para o sistema hidromorfológicos (BERGER, 2013).

Dentro do mesmo contexto e visando conceituar o termo "sistema hidromorfológicos" Goerl et al (2012 p. 104), propõe em sua revisão conceitual da Hidrogeomorfologia a busca da definição, dos princípios, processos, objetivos e aplicações da ciência que conceitualmente foi proposta em 1973 por Scheidegger em um artigo científico publicado no Journal of Hydrology, o pesquisador foi o primeiro a definir Hidrogeomorfologia "como sendo o estudo das formas causadas pela ação das águas, sendo que, por esta definição, quase toda a Geomorfologia pode ser enquadrada como tal, pois a água é o principal agente modelador da paisagem”.

Diante da necessidade de contribuir com a elucidação do conceito da Hidrogeomorfologia Goerl et al. (2012 p. 109), propõe a seguinte definição "a Hidrogeomorfologia é uma ciência que busca compreender como os processos hidrológicos contribuem para a formação e evolução da paisagem e ainda como as formas de relevo condicionam ou controlam os processos hidrológicos em diferentes escalas temporais e espaciais". Além de propor a definição do termo hidrogeomorfologia o autor aborda com base nos estudos bibliográficos por ele realizado, que o objeto de estudo da hidrogeomorfologia são os processos hidrogeomorfológicos.

Segundo Hungr et al. (2001) e Montgomery et al. (2003) os processos hidrogeomorfológicos podem ser classicados em inundações, fluxos hiperconcentrados e fluxos de detritos (debris flow).

Goerl et al. (2012), reafirma que estes processos não restringem apenas as inundações, os fluxos hiper-concentrados e os fluxos distritos, menciona que outros processos hidrogeomorfológicos podem ser identificados e associa que a sua classificação deva ocorrer a medida que se identifique que estes processos exerçam "controle tanto sobre a evolução e formação da paisagem como sobre os processos hidrológicos".

Goerl et al. (2012) acrescenta:

A Hidrogeomorfologia possui assim fundamentos da hidrologia e da geomorfologia, mas deve também possuir elementos próprios. Dessa maneira, um processo hidrológico propicia a modificação, evolução ou formação de uma feição que por sua vez condiciona a intensidade, magnitude, duração do processo hidrológico. Ou seja, o processo modifica a forma que por sua vez condiciona o processo.

Segundo Moroz-Caccia e Rodrigues (2017), uma das ferramentas que auxiliam os pesquisadores no reconhecimento dos prováveis impactos ambientais hidrogeomorfológicas de origem antrópica, é a cartografia temporal e evolutiva, que possibilitam o reconhecimento das representações da morfologia antes e depois do processo urbanização. Diante da necessidade de gerar respaldo científico de suas abordagens sobre as alterações hidrogeomorfológicas, os autores elaboram um estudo 
que avalia as mudanças morfológicas e seus efeitos hidrodinâmicos do processo de urbanização na bacia hidrográfica do rio Tamanduateí - região Metropolitana de São Paulo. Como resultado desta pesquisa foram gerados três mapas geomorfológicos, essas representações visam a apresentação da paisagem sem a ocupação urbana, após o processo de urbanização e o última mapa tem como objetivo representar as alterações dos canais fluviais elaborado com base na cartografia pré processo de urbanização, cartas topográficas e fotográfias atuais da áreas de estudo.

Atrelado a análise dos produtos cartográficos e as alterações antrópicas, MorozCaccia e Rodrigues e Rodrigues (2017), propõem a análise dos "indicadores de materiais superficiais e cobertura vegetal para planícies de inundação", estes podem ser identificados a partir do reconhecimento de áreas com interferência do processo de impermeabilização, mas que mantém parte da morfologia semipreservadas, "indicadores de morfologia (parâmetros comprimento e padrão) dos canais fluviais", neste caso as feições são reconhecidas a partir da análise das dimensões dos canais fluviais e suas alterações ao longo do processo de ocupação do solo e "indicadores hidromorfológicos para as planícies de inundação", reconhecidos através da comparação de áreas semipreservadas as quais possuem sistema de drenagem adaptado para as ocorrências de processo de inundação de áreas não adaptadas para tais eventos, e "indicador hidromorfológico nos conjuntos de vertentes", identificado através do comportamento das morfologias originais e comportamento hidrodinâmico de ambientes os quais foram submetidos a processos antropogênico.

Dentre as ferramentas propostas, a cartografia geomorfológica vem aprimorando seu patrimônio metodológico, criando recursos gráficos capazes de representar e designar os fatores geomorfológicos antropogênicos, causados através da modificação do relevo, além disso, a adoção da cartografia geomorfológica vinculada ao reconhecimento e identificação dos geoindicadores auxiliam no diagnóstico dos problemas ambientais identificados em paisagens que são submetidas as mudanças antropogênicas (NETO et al., 2017).

Segundo Berger (1997), a adoção dos geoindicadores auxiliam os pesquisadores na compreensão dos possíveis impactos ambientes e a obtenção da sustentabilidade. Em se tratando dos geoindicadores para identificação dos impactos ambientais negativos, eles indicam relevância mostram no aporte e levantamento de informações que auxiliem o pesquisador no mapeamento de áreas com indícios de impactos ambientais, associando assim, as possíveis causas e possibilitando caracterizar estas alterações dentre as referências de geoindicadores.

Os geoindicadores desempenham o papel de avaliar as mudanças associadas a interferências antrópicas que causam efeitos para o ambiente e para os habitantes das regiões que sofrem estes impactos. Embora o direcionamento da aplicação da metodologia esteja diretamente associado a mudança abiótica, os sistemas biológicos e geológicos também estão presentes nestas modificações causadas pelas ações antrópicas, não podendo assim ignorar os organismos vivos, a comprovação deste fato está 
relacionada a influência destes nos processos de intemperismo, erosão e deposição (BERGER, 1997).

Outra abordagem que merece atenção é a necessidade de aprimoramento da distinção dos níveis de impactos das ações antrópicas aos processos naturais, essa abordagem pode ser realizada através do aprofundamento das pesquisas na área de Geomorfologia, possibilitando assim, a determinação de novos conceitos das interferências antropogênicas ao meio ambiente. Em sua proposta Coltrinari (2001), aponta a necessidade de adoção e atualização das técnicas de campo e laboratório atrelado ao interesse das pesquisas multidisciplinares e impulsionam a ampliação das pesquisas aplicadas em Geomorfologia. Afirma também, que os resultados de pesquisas realizadas em áreas de risco natural que sofreram com as mudanças de paisagem de origem antrópicas podem contribuir na geração de novos conceitos sobre a influência destas ações sobre o meio ambiente (COLTRINARI, 2001).

Existe a tendência de que a compreensão dos geoindicadores passem a ser avaliados fora da Geomorfologia, o autor destaca, como exemplo, a possível contribuição dos projetos de pesquisa desenvolvidos pela COST (Cooperação Europeia na Pesquisa Científica e Técnica), estas pesquisas podem auxiliar na obtenção das respostas quanto a distinção dos níveis de impacto das ações antrópicas aos processos naturais (COLTRINARI, 2001).

As considerações sobre os geoindicadores citados por Gupta (2002), estão relacionados a importância de se manter uma infraestrutura mínima de material (instrumentos) e pessoal para monitorar, medir e gerenciar aqueles indicadores plausíveis de serem monitorados através de instrumentos. Aponta a tendência de desenvolvimento de novos instrumentos que possam auxiliar no monitoramento dos geoindicadores, além das considerações relacionadas a infraestrutura. $\mathrm{O}$ autor também aponta que não é possível projetar uma lista de indicadores padrão, existem fatores como por exemplo, a localização, que podem gerar novos geoindicadores a partir de uma análise específica presente em determinada região.

As propostas de monitoramento apresentadas por Berger (1996), Gupta (2002), Coltrinari (2001), Rodrigues (2010), possuem particularidades quanto a afirmação de que a ocorrência dos geoindicadores propostos em suas respectivas pesquisas são responsáveis pela ocorrência e desencadeamento da degradação ambiental, potencializando seus efeitos em regiões de clima tropical, em especial em áreas de clima úmido. Enfatizam também as limitações em estabelecer os diferentes níveis de impacto das ações antrópicas das de ocorrências naturais em áreas que já passaram pelo processo de urbanização.

Percebe-se que os geoindicadores são instrumentos importantes que podem auxiliar no desenvolvimento de pesquisas que visam a identificação dos impactos ambientais ocasionados a partir dos processos de urbanização, auxiliando assim, na identificação das possíveis alterações e suas influências nas modificações hidrogeomorfológico de uma determinada bacia hidrográfica. Em estudos futuros esta 
ferramenta poderá auxiliar na caracterização de indicadores que comprovem que sua ocorrência ocasiona e ou agrava os processos inundações em centros urbanos.

Dentro da perspectiva de identificação de modificação hidrogeomorfológicas em áreas urbanas, identifica-se a possibilidade de utilização de geoindicadores de avaliação de processos erosivos, morfometria e morfologia das vertentes, movimentos de massa e indícios de movimentos futuros, intensidade de inundações, alteração dos canais fluviais, alteração da qualidade da água, devido a contaminação originada a partir dos rejeitos domésticos, alteração da cobertura do solo, impermeabilização do solo, avaliação dos índices de precipitação, mudanças qualitativas e quantitativas na cobertura vegetal.

Além dos geoindicadores já referenciados nesta revisão sistemática, vale ressaltar a importância da utilização da ferramenta do sistema de informações geográficas (SIG), que possibilitará o reconhecimento, comparação e análise das modificações temporais identificadas nas representações da morfologia antes e depois do processo de urbanização. Os resultados que podem ser obtidos a partir da adoção da cartografia temporal na análise dos prováveis geoindicadores de impactos ambientais de origem antrópica, se tornam fundamentais para o embasamento e enriquecimento dos dados de comprovação da pesquisa que visará a obtenção de resultados qualitativos e quantitativos que comprovem que as ações antrópicas geram influências negativas e ou aceleram os processos de modificação hidrogeomorfológicas, contribuindo assim na ocorrência de inundações identificadas atualmente em centros urbanos.

\section{Considerações finais}

As propostas dos autores descritas nesta revisão bibliográfica são unanime à medida que colocam o homem no cenário de agente hidrogeomorfológico e apresentam propostas de geoindicadores que auxiliam no reconhecimento das prováveis mudanças ambientais de origem antrópica identificadas em ambientes onde seja perceptível o processo de urbanização. Correlacionam também, que a adoção destes geoindicadores auxiliam na compreensão da extensão temporal destas modificações ocasionadas a partir do processo de urbanização. Além disso, associam que o processo de urbanização é um dos agentes responsáveis pela modificação da paisagem, gerando assim impactos ambientais significativos.

Conclui-se que a adoção de geoindicadores se tornam instrumentos importantes na análise de ambientes que passaram por processo de urbanização. Auxiliando assim, na identificação das prováveis modificações hidrogeomorfológicas de uma determinada bacia hidrográfica. Está caracterização poderá ser feita com base em uma análise das modificações da paisagem no espaço e escalas temporais distintas em busca de associar se a ocorrência destas modificações pode agravar os processos de inundações em centros urbanos. 
A possibilidade de utilização dos geoindicadores de reconhecimento de modificações hidrogeomorfológicas em determinada bacia hidrográfica inseridas em áreas urbanas se torna uma ferramenta preventiva no planejamento urbano.

Sendo assim, pode atribuir que os geoindicadores a medida que forem utilizados como ferramentas preventivas em ambientes urbanizados com indícios de impactos ambientais significativos possam tornar uma ferramenta de auxilio no planejamento urbano, visando minimizar os impactos ambientais causados.

As críticas apresentadas quanto a adoção e aplicação dos geoindicadores em estudos ambientais está voltada para a necessidade de que as pesquisas e estudos de caso da área, gerem resultados concretos de forma que possam distinguir as mudanças de curto prazo que afetam o equilíbrio da natureza, das geradas devido a causas naturais e ou ações antrópicas. Sendo assim, um dos desafios observados nesta revisão é a necessidade de aperfeiçoar a etapa de distinção dos impactos causados por ações antropogênicas das ações naturais. Existe a necessidade de tornar mais precisa a quantificação das alterações causadas através das ações antrópicas daquelas que consequentemente já ocorreriam dentro de uma escala temporal maior.

Outro ponto relevante na abordagem descrita nesta revisão e referenciado é o fato dos geoindicadores não abordarem os fatores bióticos e abióticos, a ausência desta abordagem se torna preocupante, tendo em vista que estes processos também influenciam e contribuem para a modificação dos ecossistemas.

O desafio atrelado ao aperfeiçoamento da ferramenta dos geoindicadores na identificação dos impactos ambientais ocasionados pelo processo de urbanização, está relacionado a necessidade de uma ampla multidisciplinaridade, para que junto com outras áreas possam ser definidos geoindicadores mais eficientes que auxiliam as cidades na avaliação e tomada de decisão durante a fase de planejamento urbano.

\section{Referências Bibliográficas}

BERGER, A. R. Assessing rapid environmental change using geoindicators. Environ. Geol., v. 32, n. 1, p. 36-44, 1997.

COLTRINARI, L. Mudanças ambientais globais e geoindicadores. Pesquisas em Geociências, Porto Alegre, v. 28, n. 2, p. 307-314, maio/ago. 2001.

DIVISÃO DAS NAÇÕES UNIDAS PARA A POPULAÇÃO DO DEPARTAMENTO DOS ASSUNTOS ECONÓMICOS E SOCIAIS (DESA). Perspectivas da Urbanização

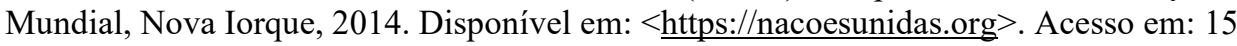
janeiro 2019.

GOERL, R. F.; KOBIYAMA, M.; SANTOS, I. Hidrogeomorfologia: princípios, conceitos, processos e aplicações. Laboratório de Hidrogeomorfologia/UFPR, 2011.

GOUDIE, A. Human influence in geomorphology. Geomorphology, v. 7, p. 37-59, 1993. 
GUPTA, A. Geoindicators for tropical urbanization. Environmental Geology, v. 42, p. 736-742, 2002.

HUNGR, O.; EVANS, S. G.; BOVIS, M. J.; HUTCHINSON, J.N. A review of the classification of landslides of the fl ow type. Environmental and Engineering Geoscience, v. 7, n. 3, p. 221-238, 2001.

LUZ, R. A. Mudanças geomorfológicas na planície fluvial do Rio Pinheiros, São Paulo (SP), ao longo do processo de urbanização. 2015, 245p. Tese (Doutorado em Geografia), Faculdade de Filosofia, Letras e Ciências Humanas, Universidade de São Paulo. São Paulo, 2015.

MOHER D, LIBERATI A, TETZLAFF J, ALTMAN DG, PRISMA Group: Preferred reporting items for systematic reviews and meta-analyses: the PRISMA Statement. BMJ 2009. Tradução Taís Freire Galvão e Thais de Souza Andrade Pansani; retro-traduzido por: David Harrad.

MONTGOMERY, D. R.; BOLTON, S. M. Hydrogeomorphic Variability and River Restoration. In: ISSMAR, R. C. e BISSON, P. A. (ed.) Strategies for Restoring River Ecosystems: Sources of Variability and Uncertainty in Natural and Managed Systems. American Fisheries Society Publication: Maryland, p. 39-80, 2003.

MOROZ-CACCIA, G. I.; RODRIGUES, C. Mudanças morfológicas e efeitos hidrodinâmicos do processo de urbanização na bacia hidrográfica do rio Tamanduateí - Região Metropolitana de São Paulo. Geousp - Espaço e Tempo (Online), v. 21, n. 1, p. 257-283, abril. 2017.

NETO, R. M.; SILVA, F. P. de; FERNANDES, R. A. de; BARRETO, J. C.; EDUARDO, C. C. A espacialidade do relevo em paisagens transformadas e sua representação: Mapeamento geomorfológico da bacia do rio Paraibuna, sudeste de Minas Gerais. R. Ra'e Ga, Curitiba, v. 41 Temático de Geomorfologia, p. 65 -81, Ago/2017.

NIR, D. (1983) Man, a geomorphological agent: an introduction to anthropic geomorphology. Jerusalem, Ketem Pub. House.

PELOGGIA, A. U.G. A cidade, as vertentes e as várzeas: a transformação do relevo pela ação do homem no município de São Paulo. Revista do Departamento de Geografia, n.16, p.24-31, 2005.

RODRIGUES, C. Avaliação do impacto humano da urbanização em sistemas hidrogeomorfológicos. Desenvolvimento e aplicação de metodologia na grande São Paulo. Revista do Departamento de Geografia, São Paulo, n. 20, p. 111-125, 2010. 


\section{Ana Carolina Barbosa Pereira Dinotte}

Mestranda no programa de Desenvolvimento Sustentável e Tecnologia Ambiental do Instituto Federal de Educação, Ciência e Tecnologia de Minas Gerais, especialista em Gestão da Qualidade Integrada ao Meio Ambiente pela Pontifícia Universidade Católica de Minas Gerais, graduada em Geografia e Análise Ambiental pelo Centro Universitário de Belo Horizonte, professora convidada em cursos de pós graduação na Pontifícia Universidade Católica de Minas Gerais e Analista de Sistema Integrado de Gestão na TSEA Energia.

Rua k, 50, Bairro Colorado, Contagem - Minas Gerais, CEP: 32.143.310

E-mail: anacarolinna1@yahoo.com.br

\section{Cecília Félix Andrade Silva}

Doutora em Geografia pela Universidade Federal de Minas Gerais, mestre em Ciência Florestal pela Universidade Federal de Viçosa, graduada em Geografia pela Universidade Estadual do Sudoeste da Bahia, professora efetiva do Instituto Federal de Educação, Ciência e Tecnologia de Minas Gerais.

Rua Pangiá Calógeras,898, Bairro Bauxita, Ouro Preto - Minas Gerais, CEP: $35400-000$

E-mail: cecilia.andrade@ifmg.edu.br

\section{Hygor Aristides Victor Rossoni}

Doutor em Saneamento, Meio Ambiente e Recursos Hídricos pela Universidade Federal de Minas Gerais, mestre em Ciência Florestal pela Universidade Federal de Minas Gerais, Graduado em Engenharia Ambiental pela Universidade Federal de Viçosa, professor efetivo da Universidade Federal de Viçosa.

Rodovia LMG 818, km 06, s/n - Bairro do Lago, Florestal - Minas Gerais,

CEP: $35690-000$

E-mail: hygorrossoni@yahoo.com.br

Recebido para publicação em fevereiro de 2019 Aprovado para publicação em setembro de 2019 